\title{
Heat Output from Spreading and Rifting Models of the Taupo Volcanic Zone, New Zealand
}

GRAHAM J. WEIR

Applied Mathematics, Industrial Research, New Zealand

g.weir@irl.cri.nz

\begin{abstract}
A conceptual model of the Taupo Volcanic Zone (TVZ) is developed, to a depth of $25 \mathrm{~km}$, formed from three constant density layers. The upper layer is formed from eruption products. A constant rate of eruption is assumed, which eventually implies a constant rate of extension, and a constant rate of volumetric creation in the middle and bottom layers. Tectonic extension creates volume which can accomodate magmatic intrusions. Spreading models assume this volume is distributed throughout the whole region, perhaps in vertical dykes, whereas rifting models assume the upper crust is thinned and the volume created lies under this upper crust. Bounds on the heat flow from such magmatic intrusions are calculated. Heat flow calculations are performed and some examples are provided which match the present total heat output from the TVZ of about $4200 \mathrm{MW}$, but these either have extension rates greater than the low values of about $8 \pm 4 \mathrm{~mm} / \mathrm{a}$ being reported from GPS measurements, or else consider extension rates in the TVZ to have varied over time.
\end{abstract}

Keywords: heat flow, geothermal fields, conceptual models, conduction

\section{Introduction}

The majority of geothermal activity in New Zealand is concentrated in the Taupo Volcanic Zone (TVZ). Hochstein (1995) has emphasised that the long term eruption rate of rhyolites from the TVZ is the highest on earth for a volcanic arc setting, and also that the total crustal heat transfer is arguably the highest on earth for an arc setting. The geological, geochemical and geophysical properties of the TVZ have been summarised in a Special Issue of Journal of Volcanology and Geothermal Research (Simmons and Weavers, 1995) on the TVZ. Large-scale reservoir engineering properties of the TVZ are summarised by McNabb (1975), and in the book by Elder (1976).

The location of the 23 known geothermal fields in the TVZ are plotted in Fig. 1. At least six different models (spreading, rifting, plasticity, hotplate, froth, and transtensional) have been proposed to describe some of 
Table 1. Approximate TVZ parameters.

\begin{tabular}{|c|c|c|}
\hline Symbol & Meaning & Assumed value \\
\hline$f$ & Mantle to TVZ width ratio & 1.6 \\
\hline$t$ & Time & \\
\hline$v$ & Extension rate & $13 \mathrm{~mm} / \mathrm{a}$ \\
\hline$w$ & Average TVZ width & $30 \mathrm{~km}$ \\
\hline$w_{0}$ & Initial average TVZ width & $9 \mathrm{~km}$ \\
\hline$z$ & Depth & \\
\hline$z_{1}$ & Lower infill surface depth & \\
\hline$z_{2}$ & Depth of upper Layer 3 surface & \\
\hline$z_{1 \infty}$ & Asymptotic thickness of Layer 1 & $4 \mathrm{~km}$ \\
\hline$z_{2 \infty}$ & Asymptotic thickness of Layer 2 & $7 \mathrm{~km}$ \\
\hline$z_{3 \infty}$ & Asymptotic thickness of Layer 3 & $14 \mathrm{~km}$ \\
\hline$z_{3}$ & Depth of mantle & $25 \mathrm{~km}$ \\
\hline$z_{b d}$ & Brittle-ductile depth & $8 \mathrm{~km}$ \\
\hline$\dot{A}_{1}$ & Rate of increase of Layer 1 & $1.5 \times 10^{-6} \mathrm{~m}^{2} / \mathrm{s}$ \\
\hline$\dot{A}_{2}$ & Rate of increase of Layer 2 & $3 \times 10^{-6} \mathrm{~m}^{2} / \mathrm{s}$ \\
\hline$\dot{A}_{3}$ & Rate of increase of Layer 3 & $10 \times 10^{-6} \mathrm{~m}^{2} / \mathrm{s}$ \\
\hline$C$ & Magma specific heat & $1.3 \times 10^{3} \mathrm{~J} / \mathrm{kgK}$ \\
\hline$\dot{E}_{b d}$ & Energy flow from intrusives above $z_{b d}$ & $1000 \mathrm{MW}$ \\
\hline$K$ & Rock conductivity & $2 \mathrm{~W} / \mathrm{mK}$ \\
\hline$L$ & Magma crystallization energy & $3.5 \times 10^{5} \mathrm{~J} / \mathrm{kg}$ \\
\hline$R$ & TVZ eruption rate per unit length & $1.9 \times 10^{-6} \mathrm{~m}^{2} / \mathrm{s}$ \\
\hline$R_{G V}$ & Geothermal to erupted magma volume flows & $2-4$ \\
\hline$S$ & Average TVZ length & $200 \mathrm{~km}$ \\
\hline$T$ & Temperature & \\
\hline$T_{m}$ & Melting temperature & $1250^{\circ} \mathrm{C}$ \\
\hline$V$ & Unit volume & \\
\hline$\delta$ & Fraction of initial Layer 3 mobilised & 0.43 \\
\hline$\epsilon$ & Fraction of greywacke in rhyolite & 0 \\
\hline$\lambda$ & Fraction of rhyolite in Layer 2 & 0.4 \\
\hline$\rho_{1}$ & Layer 1 density & $2170 \mathrm{~kg} / \mathrm{m}^{3}$ \\
\hline$\rho_{2}$ & Layer 2 density & $2670 \mathrm{~kg} / \mathrm{m}^{3}$ \\
\hline$\rho_{3}$ & Layer 3 density & $2795 \mathrm{~kg} / \mathrm{m}^{3}$ \\
\hline$\theta$ & Ratio of rhyolite in Layer 2 wrt Layer 1 & 2 \\
\hline
\end{tabular}




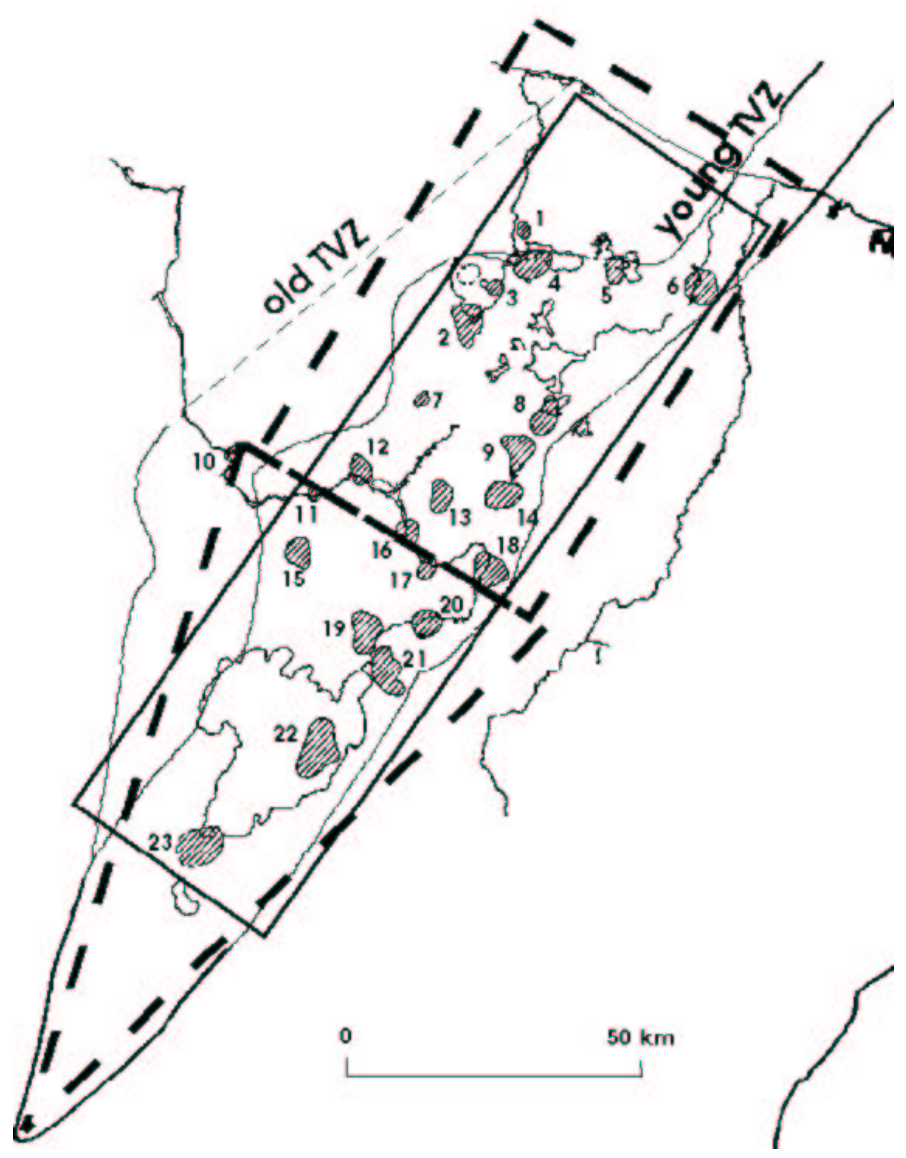

Figure 1. Area estimates for the TVZ. The shaded and labelled areas are the geothermal fields: 1.Taheke, 2.Rotorua, 3.East Rotorua, 4.Rotoiti, 5.Rotoma, 6.Kawerau, 7.Horohoro, 8.Waimangu, 9.Waiotapu-Waikite, 10.Mangakino, 11.Ongaroto, 12.Atiamuri, 13.Te Kopia, 14.Reporoa, 15.Mokai, 16.Orakeikorako, 17.Ngatamariki, 18.Ohaaki, 19.Wairakei, 20.Rotokawa, 21.Tauhara, 22.Lake Taupo, 23.Tokaanu.

the special properties of the TVZ (see Weir, 1998a). The large scale physics of the TVZ have been summarised by McNabb (1975). 


\section{Eruptive Rates and Time-scales}

The average magma flow from all of the TVZ is of the order of $1.5 \mathrm{~m}^{3} / \mathrm{s}$, formed from roughly $0.3 \mathrm{~m}^{3} / \mathrm{s}$ (Wilson et al., 1995) of extrusive magma and roughly $1.2 \mathrm{~m}^{3} / \mathrm{s}$ (Wilson et al., 1984) of magma driving the geothermal fields in the TVZ.

The highest rate of eruption reported (Wilson, 1993) for the TVZ occurred in the last 50 - $70 \mathrm{ka}$, with time-integrated rates of $3.5 \mathrm{~km}^{3} / \mathrm{ka}$ for Okataina and $6.5 \mathrm{~km}^{3} / \mathrm{ka}$ for Taupo. While these are the highest individual rhyolitic time-averaged eruption rates in the world, to account for over $15,000 \mathrm{~km}^{3}$ of rhyolites over $1.6 \mathrm{Ma}$ (Wilson et al., 1995) requires that the present rate of rhyolitic eruptions has continued for the full 1.6 Ma of TVZ's existence. Because of these reasons, a constant rate of erupted volcanic volume in the TVZ is assumed, because present data cannot warrant more detailed information.

\section{Assumed Depth Structure in the TVZ}

Analysis of the seismic velocity structure under the TVZ indicates a three layer structure (Stern and Davey, 1987; Stern, 1987). An idealised sketch of these three layers is given in Fig. 2. The upper $2.5 \mathrm{~km}$ of about $3.0 \mathrm{~km} / \mathrm{s}$ material is formed mostly from pyroclastic infill. The region between about $2.5 \mathrm{~km}$ to $15 \mathrm{~km}$ depth is occupied by $5.5-6.1 \mathrm{~km} / \mathrm{s}$ material. Adjacent greywacke has a similar seismic velocity. Material between depths of 15 and $25 \mathrm{~km}$ has a seismic velocity of $7.4-7.5 \mathrm{~km} / \mathrm{s}$ material. This region appears to be greater in width than the TVZ region above it. Mantle material adjacent to the TVZ has a seismic velocity of about $7.6 \mathrm{~km} / \mathrm{s}$.

The crust under the TVZ is perhaps only $15 \mathrm{~km}$ thick, whereas elsewhere is it typically $25 \mathrm{~km}$ thick. A major challenge for any mathematical model is to explain how the crust under the TVZ has thinned from $25 \mathrm{~km}$ to 15 $\mathrm{km}$ in the last 1.6 Ma. This is modelled in this paper, thereby extending the previous static model of Weir (1998).

\section{Transient Spreading Model}

The aim of this section is to develop approximations to the evolution of the three regions in Fig. 2 for a transient speading model. If $z$ is depth, then $z_{1}$ is the base of the pyroclastic infill region, $z_{2}$ the top of the mantle rise, and $z_{3}$ the base of the mantle rise, assumed fixed at $25 \mathrm{~km}$ depth. The height of the upper (land) surface in the TVZ region will alter with time, 


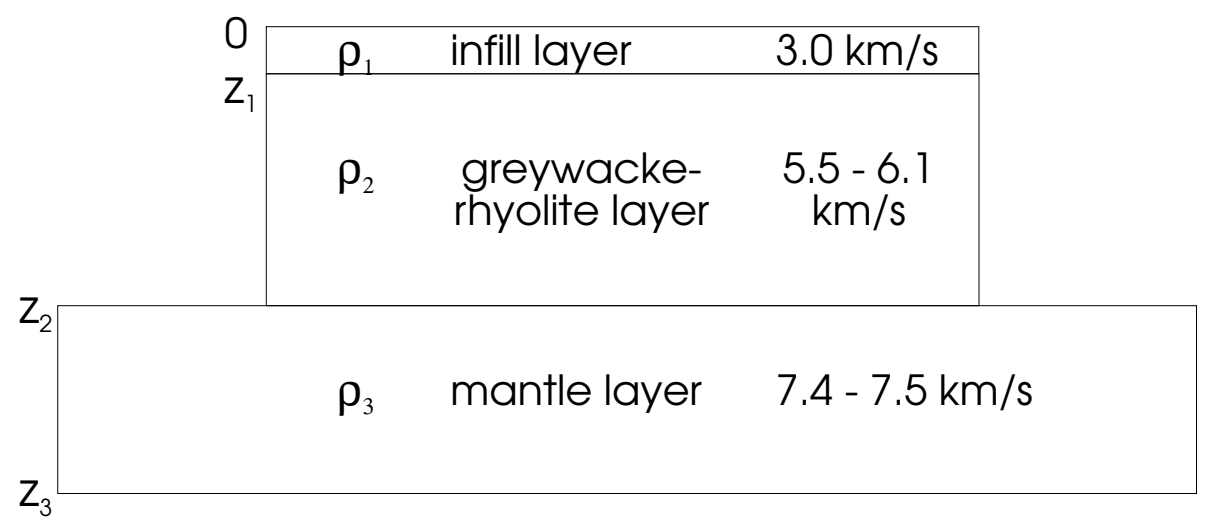

Figure 2. Assumed depth structure in the TVZ.

but this surface $(z=0)$ is assumed to be fixed in space, because its motion is small relative to the motion of the other surfaces, and little is known about its motion.

Cole (Fig. 14, 1990) suggests the middle layer $\left(z_{1} \leq z \leq z_{2}\right)$ region is formed by partial melting of volcanic and plutonic rocks, and high-level reservoirs of rhyolitic magma. The upper layer $\left(0 \leq z \leq z_{1}\right)$ is the infill layer, although this region will comprise of both infill, mostly from rhyolitic volcanism, and intrusions. For example, a diorite intrusion was discovered at Ngatamariki (Wilson et al., 1995) in the infill region. The lower region $\left(z_{2} \leq z \leq z_{3}\right)$ is the mantle region, although it is possible that its composition may differ from the mantle to the west, due to the incorporation of greywacke and earlier intrusions into the rising mantle plume, and to the entry of magma from below.

The pressure at a depth of $25 \mathrm{~km}\left(z=z_{3}\right)$ is assumed constant. Then if $\rho_{1}, \rho_{2}, \rho_{3}$ are the densities (assumed constant) of rock in Layers $1(0<z<$ $\left.z_{1}\right), 2\left(z_{1}<z<z_{2}\right), 3\left(z_{2}<z<z_{3}\right)$,

$$
\rho_{3}\left(z_{3}-z_{2}\right)+\rho_{2}\left(z_{2}-z_{1}\right)+\rho_{1} z_{1}=\rho_{2} z_{3}
$$

where it is also assumed that the initial density of the rock is the density of the middle layer. These two assumptions are not exactly true, as a pressure difference above lithostatic is needed to drive rock upwards. This pressure difference may be relatively small, given the transient time scale for such processes is of the order of $0.01 \mathrm{Ma}$ (Weir, 1998), whereas the rifting processes in the TVZ have been occurring for 1.6 Ma. Also, mixing 
of greywacke and igneous intrusions, for example, will alter the density in the middle layer.

Rearranging (1) shows that

$$
\left(\rho_{2}-\rho_{1}\right) z_{1}=\left(\rho_{3}-\rho_{2}\right)\left(z_{3}-z_{2}\right)
$$

and so the thickness of pyroclastic infill is proportional to the height of the mantle rise. In Fig. 2 the width of the pyroclastic infill is assumed proportional to the width of the mantle rise, so (2) also implies the volume of total extruded volcanics in the TVZ is proportional to the volume of the mantle rise. This theoretical argument is then analogous, though different, to the observation that there is an approximate proportionality between magma volumes and extrusive volumes at some locations. It is shown below that the transient spreading model also has the property of a constant ratio between geothermal volumetric magma flows and erupted volumes.

The assumption above that the density of rock remains constant in each layer imposes strong constraints on the nature of the intrusions in the TVZ which can be considered in such a model. If a significant amount of rhyolite is intruded into the upper layer, then the average density there could vary over time. Below it is assumed that geothermal heating mostly results from magmatic intrusions into the middle layer, because most of the heat associated with the formation of the upper layer will be lost to the atmosphere on being deposited onto the upper surface after eruption.

Once material in the mantle rise region reaches the mantle-greywacke interface, the greywackes will be both contaminated and mobilised, and a fraction $\delta$ moves upwards, with the cooled remnant and contaminated mantle material tending to form the rising mantle plume, replacing volume lost by the mobilised greywacke.

If the average width of the TVZ is $w$, and this increases with time, starting from an initial average width of $w_{0}$, then the increase in incremental mass (per unit length of the TVZ) incorporated into the TVZ region from the rise in the upper surface of the mantle plume equals the increase in mass in the middle and upper layers in the TVZ.

$$
\delta \rho_{2} d\left[f w\left(z_{3}-z_{2}\right)\right]=\rho_{2} d\left[w\left(z_{2}-z_{1}\right)\right]+\rho_{1} d\left(w z_{1}\right)
$$

The factor $f$ has been included in (3) because the average width of the mantle rise in layer 3 appears to be about $1.5-1.7$ times greater than the width of the middle layer (Stern and Davey, 1987). However, $f$ could also be about one (Cole, Fig. 14, 1990), if the mantle plume is moving upwards, roughly parallel to the descending oceanic plate. The constant factor $\delta$ in (3) equals the fraction of Layer 3 mobilised into Layers 1 and 2. The left 
hand side of (3) is the mass (density $\rho_{2}$ ) initially outside, but about to be covered by Layer 3 .

Integrating (3), using the initial conditions and (1) yields

$$
z_{3}-z_{2}=z_{3 \infty}\left(1-\frac{w_{0}}{w}\right)
$$

where

$$
z_{3 \infty}=\frac{\rho_{2} z_{3}}{\rho_{3}+f \delta \rho_{2}}
$$

which, strangely, is independent of $\rho_{1}$. As $w$ increases, and becomes much larger than $w_{0}$, then the thickness of Layer 3 tends upwards towards $z_{3 \infty}$.

Taking $\rho_{2}$ as $2670 \mathrm{~kg} / \mathrm{m}^{3}$ (Fig. 13, Davey et al., 1995), $\rho_{1}$ as $2170 \mathrm{~kg} / \mathrm{m}^{3}$ (Modriniak and Studt, 1959), then from (1) $\rho_{3}$ is $2795 \mathrm{~kg} / \mathrm{m}^{3}$, provided at this time (see Fig. 2) $z_{3}$ is $25 \mathrm{~km}, z_{1}$ is $2.5 \mathrm{~km}$ and $z_{2}$ is $15 \mathrm{~km}$. Consequently, Layer 3 has a density much less than basalt (about 3300 $\mathrm{kg} / \mathrm{m}^{3}$, Table 1, Wilcox, 1976).

From (4), the final thickness of Layer 3 must be greater or equal to its present thickness, and using the density values above,

$$
f \delta \leq 1.45
$$

It remains to determine $f \delta$ and $w_{0}$, and the dependence of $w$ on time. This is done by choosing a constant eruptive rate, and then considering constraints on $f \delta$.

From Fig. 2, a constant rate of eruption is assumed,

$$
w z_{1}=R t=\frac{\left(\rho_{3}-\rho_{2}\right) \rho_{2} z_{3}\left(w-w_{0}\right)}{\left(\rho_{2}-\rho_{1}\right)\left(\rho_{3}+f \delta \rho_{2}\right)}
$$

where (2), (4) and (5) have been used. From (7), w must increase linearly with time. The volume in the middle layer also increases linearly in time, since from (2), (4) and (7),

$$
\left(z_{2}-z_{1}\right) w-z_{3} w_{0}=R_{G V} R t
$$

where

$$
R_{G V}=\frac{\left(\rho_{2}-\rho_{1}\right) f \delta}{\left(\rho_{3}-\rho_{2}\right)}-\frac{\rho_{1}}{\rho_{2}} \leq 5
$$

and the inequality in (9) follows from that in (6).

The left hand side of (8) is the increase in volume of the middle layer (per unit length), which must represent a flow of magma from the mantle rise region. The inflow rate of this magma is then a constant, since (8) shows a linear increase with time. Since $R t$ is the erupted rate of magma (per 
unit length) onto layer $1, R_{G V}$ is the ratio of the volume of magma flow into the middle layer (which presumably fuels the geothermal fields in the TVZ) to the volume of magma extruded in the TVZ. $R_{G V}$ is independent of the initial width of the TVZ, and is less than 5, if the model is to be consistent with the present rise of the mantle under the TVZ.

The cumulative volume of magma in the middle layer per unit length of the TVZ is $R_{G V} R t$, in (8). Then the rate of mass flow into the middle layer, per unit volume, is

$$
\frac{1}{V} \frac{d M}{d t}=\frac{\rho_{2} R_{G V} R}{z_{3} w_{0}+R_{G V} R t}
$$

which decreases monotonically with time.

\section{Transient Heat Flow Model in the Ductile Layer}

It is widely accepted that fracture surfaces in rocks with a temperature of over about $400^{\circ} \mathrm{C}$ tend to creep together (Turcotte and Oxburgh, 1972). Such rocks are called ductile. The removal of fractures in ductile rocks dramatically reduces their permeability, and in this paper, it is assumed that convection of meteoric groundwater is insignificant in ductile rocks. It has been suggested (Bibby et al, 1995, McNabb and McKibbin, 1998) that rocks become ductile in the TVZ at a depth of below about $8 \mathrm{~km}$. It is assumed that any magma entering the brittle region will be cooled by circulating meteoric water to under $400^{\circ} \mathrm{C}$, and the heat transported to the surface.

The equation describing conductive heat transport in the ductile region (where convective heat transport by meteoric water is assumed to be insignificant) in the presence of magmatic intrusions is

$$
\rho_{2} C \frac{\partial T}{\partial t}=\frac{\partial}{\partial z} K \frac{\partial T}{\partial z}+\frac{1}{V} \frac{d M}{d t}\left[C\left(T_{m}-T\right)+L\right]
$$

where $C$ is the heat capacity of the rock, $T$ is temperature, $t$ time, $K$ thermal conductivity, $T_{m}$ the molten temperature of the magma, and $L$ is the latent heat of the magma. In all calculations, $K=2 \mathrm{~W} / \mathrm{mK}$ (Clauser and Huenges, 1995).

Equation (11) is solved subject to an initial temperature distribution which is linear with depth, with a temperature of $400^{\circ} \mathrm{C}$ at the brittle ductile surface $(z=8 \mathrm{~km})$, and a temperature of $T_{m}$ at the surface $z=z_{2}$.

The mass flow per unit volume term, in the transient calculations, was taken as

$$
\frac{1}{V} \frac{d M}{d t}=\frac{\rho_{2} v}{w}
$$




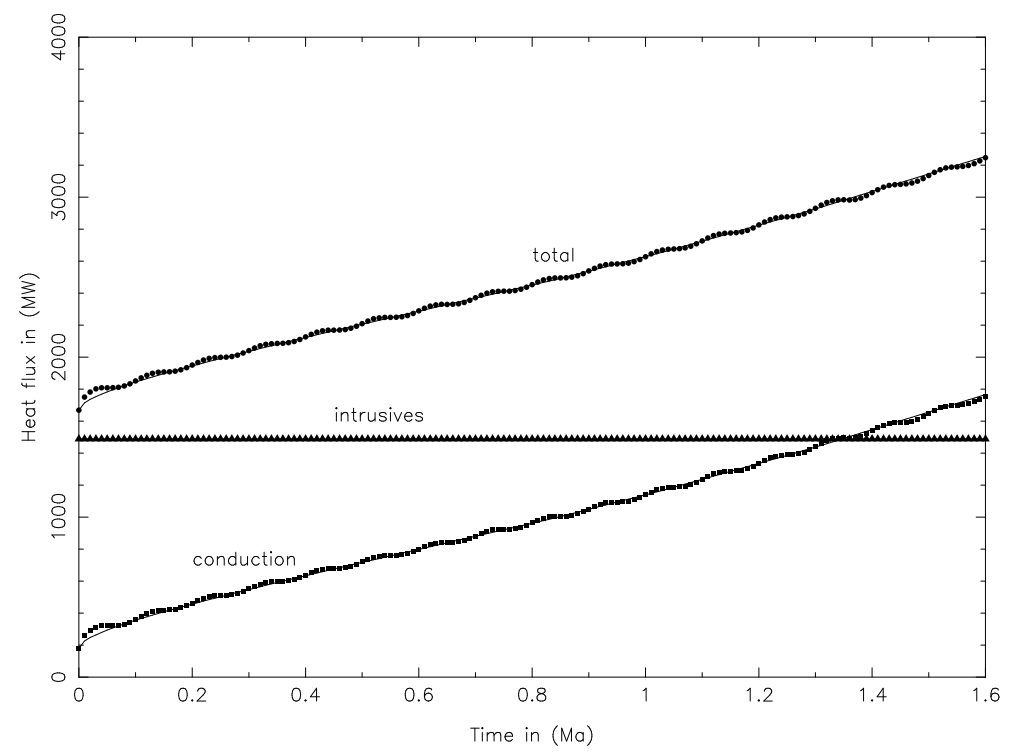

Figure 3. Surface heat flows (MW) as functions of time (Ma) for a spreading rate of 13 $\mathrm{mm} / \mathrm{a}$, and for $f \delta=0.7$.

which corresponds to the TVZ increasing in width at rate $v$ over a fixed height, where $\rho_{2}$ is the density of Layer 2 , of width $w$. Here we assume

$$
w=w_{0}+v t+\frac{1}{2 \pi} \sin (20 \pi t)
$$

because (13) implies maxima in volcanic activity every .1Ma, and a velocity of opening of $v \pm 10 \mathrm{~mm} / \mathrm{a}$.

The corresponding total surface heat flows are shown in Fig. 3. The solid lines correspond to a constant opening rate of $13 \mathrm{~mm} / \mathrm{a}$, and the broken lines correspond to (13). The conductive heat flow at 1.6 Ma of about $1800 \mathrm{MW}$ corresponds to a heat flux of about $0.3 \mathrm{~W} / \mathrm{m}^{2}$ (for $f \delta=0.7$ ). Simulations show there is an approximately linear increase at $1.6 \mathrm{Ma}$ in heat flux from about $0.3 \mathrm{~W} / \mathrm{m}^{2}$ to $0.45 \mathrm{~W} / \mathrm{m}^{2}$, as $f \delta$ increases from 0.7 to 1.4. The increase of conductive heat with time (at about 1.6 Ma) is due mostly to the increasing surface area of the TVZ.

The contribution to the energy flow from intrusives $\dot{E}_{b d}$ is constant, from (4), (5), (2) and (11),

$$
\dot{E}_{b d}=\left(z_{b d}-z_{1 \infty}\right) \rho_{2}\left(C\left(T_{m}-T_{b}\right)+L\right) S v
$$


because the rate of volume creation above a fixed depth in Layer 2 is constant. In (14), $z_{b d}$ is the fixed brittle-ductile depth of $8 \mathrm{~km}$. These values show that both conduction (1800 MW) and intrusives (1500 MW) contribute about equal energy flows at present, although earlier the majority of the heat flow resulted from intrusives.

These heat flow calculations show that the variable opening rate (of 0.1 Ma period) does not significantly affect the total heat flows. If about 1000 MW of energy are added from an andesitic water flow (Weir, 1998), then total heat flows similar to those occurring in the TVZ (4200 MW) result. However, to achieve this result, it has been necessary to use an extension rate $(13 \mathrm{~mm} / \mathrm{a})$ considerably greater than is measured at present $(8 \mathrm{~mm} / \mathrm{a})$.

\section{Transient Rifting Model}

Chemical and isotopic analyses suggest (Graham et al., 1995) that TVZ rhyolite appears to be mostly of andesitic composition, with only a small amount of greywacke present. This suggests that the rock originally occupying Layer 3 was mostly andesite, as suggested by Cole (1990), and this requires an immense amount of andesite to initially underlie the TVZ, and also a large deep heat source. One way to circumvent these difficulties is by allowing the volume occupied by Layer 3 to be formed by rifting Layers 1 and 2 apart. Layer 3 would then be formed from andesite and other components, some of which would flow up into Layers 1 and 2, being slightly contaminated by greywacke, to form rhyolite. Some of this rhyolite must remain within Layer 2 to provide the heat and chemicals for the geothermal fields in the TVZ.

For simplicity, it is assumed that greywacke originally occupies the volume of Layer 3, and that rifting occurs, so that no greywacke is present in Layer 3. Then conservation of greywacke requires

$$
\rho_{2}(1-\lambda+\epsilon \lambda)\left(z_{2}-z_{1}\right) w+\rho_{1} \epsilon z_{1} w=\rho_{2} z_{3} w_{0}
$$

where $\epsilon$ is the mass fraction of greywacke in rhyolite and $\lambda$ is the volume fraction of rhyolite in Layer 2. Layer 1 is assumed to be fully occupied by rhyolite, and so the c. $5 \%$ of other eruptive types have been ignored in Layer 1.

Defining

$$
\theta=\frac{\lambda\left(z_{2}-z_{1}\right)}{z_{1}}
$$


where $\theta$ is the volume ratio between stored rhyolite in Layer 2 to that in Layer 1, and using (2), (15) and (16) yields

$$
z_{3}-z_{2}=z_{3 \infty}\left(1-\frac{w_{0}}{w}\right)
$$

where

$$
z_{3 \infty}=\frac{z_{3}}{\left[1+\frac{\left(\rho_{3}-\rho_{2}\right)}{\left(\rho_{2}-\rho_{1}\right)}\left(1+\theta(1-\epsilon)-\frac{\rho_{1} \epsilon}{\rho_{2}}\right)\right]}
$$

In the limit that $\theta=2, \epsilon=0,\left(\rho_{2}-\rho_{1}\right) /\left(\rho_{3}-\rho_{2}\right)=4$, then $z_{3 \infty}=4 z_{3}$ /7. The asymptotic thicknesses of Layers 1 and 2 are then $z_{1 \infty}=z_{3} / 7$ and $z_{2 \infty}=2 z_{3} / 7$, respectively. The asymptotic value of $\lambda$ is two, from (16), for the selected values above.

Since (17) is formally identical to (4), these rifting and spreading models both have constant rates of increase of layer areas, and so the motions of the interfaces satisfy

$$
\begin{gathered}
z_{1}=\frac{\dot{A}_{1} t}{w}=\frac{R t}{w} \\
z_{2}-z_{1}=\frac{\dot{A}_{2} t+z_{3} w_{0}}{w} \\
z_{3}-z_{2}=\frac{\dot{A}_{3} t}{f w}
\end{gathered}
$$

where $\dot{A}_{1}, \dot{A}_{2}$ and $\dot{A}_{3}$ are the rates of increase of area for Layer 1, 2 and 3 respectively. Adding (19), (20) and (21) yields

$$
z_{3} v=\dot{A}_{1}+\dot{A}_{2}+\frac{\dot{A}_{3}}{f}
$$

From (19) - (21), the asymptotic values of the Layer thicknesses $z_{1 \infty}, z_{2 \infty}$ and $z_{3 \infty}$ equal $\dot{A}_{1} / v, \dot{A}_{2} / v$ and $\dot{A}_{3} / f v$, respectively.

From (16), $\dot{A}_{2}=\theta \dot{A}_{1}$, and so from (19) and (20),

$$
\frac{w}{v}=\frac{z_{3} t}{z_{3}+(1+\theta) z_{1}-z_{2}}
$$

and for $\theta$ about 2, the ratio of $w$ to $v$ is fixed (at about $2.3 \mathrm{Ma}$ ), since all the terms on the right hand side of (23) are known at present. Note that (23) is independent of $\dot{A}_{3}$, because in this rifting model, there is no relationship between volumes below $z_{2}$ and those above $z_{2}$.

Choosing $w=30 \mathrm{~km}$, then from (23), $w_{0}=9 \mathrm{~km}$, and $v=13 \mathrm{~mm} / \mathrm{a}$. Choosing $\theta$ as 2, and using present layer depths, gives $\lambda$ as 0.4 from (16), and so for these values and this rifting model, Layer 2 is about $40 \%$ full of 
rhyolite. Similarly, the Layer areas increase as $\dot{A}_{1}=1.5 \times 10^{-6} \mathrm{~m}^{2} / \mathrm{s}, \dot{A}_{2}=$ $3 \times 10^{-6} \mathrm{~m}^{2} / \mathrm{s}$, and $\dot{A}_{3}=10 \times 10^{-6} \mathrm{~m}^{2} / \mathrm{s}$ for $f=1.6$. Thus volume is being created much faster in Layer 3 than it can be removed above, and so the displaced greywacke initially occupying Layer 3 must be moved out of the TVZ region, probably mostly under the North Island Shear Belt (NISB), which must move to the east in response to this flow of incoming rock. Thus uplift of the Axial Ranges of the NISB, erosion and or displacement is needed in this model. "Major uplift and dissection west, south and east of the TVZ between c. $1 \mathrm{Ma}$ and c. $0.34 \mathrm{Ma}$ " is reported by Wilson et al. (p.21, 1995).

Since this transient rifting model has the same extension rate $(13 \mathrm{~mm} / \mathrm{a})$ and initial width $(9 \mathrm{~km})$ as the transient spreading model above, for $\theta=$ 2 , the two models have identical thermal histories. The main difference between the two models then is the composition of Layer 3 . The spreading model requires that about $56 \%$ of Layer 3 is greywacke, but in the rifting model, no greywacke is present in Layer 3.

\section{Discussion and Conclusions}

A three layer model between the surface and a depth of $25 \mathrm{~km}$ was formulated. Material erupts onto the surface, forming Layer 1, to balance the higher density material in Layer 3 . The predicted heat output of the model contained a component from intrusions above $8 \mathrm{~km}$ which tended to produce a constant heat flow with time of about $1000 \mathrm{MW}$. Intrusives below 8 $\mathrm{km}$ produced an increasing conductive heat flow with time (because of the increasing surface area), which now could be about 2000 MW. Additional to this may be another $1000 \mathrm{MW}$ from andesitic water.

Rising material which stops at a depth above about $8 \mathrm{~km}$ is cooled by circulating meteoric water to release its heat and chemicals into rising geothermal plumes. Material which stops below about $8 \mathrm{~km}$ depth can contribute some heat by conduction to the circulating groundwater above about $8 \mathrm{~km}$ depth. Additionally, andesitic water to the east will enter the geothermal plumes, adding chemicals and heat there.

A model valid throughout the 1.6 Ma of the TVZ was not found. No heat model for the basic heat source driving the TVZ was presented. However, if the mechanisms operating in the TVZ are those of spreading, or of rifting, then the simple models above showed that, to be consistent with the heat flow and seismic records, required spreading rates $(13 \mathrm{~mm} / \mathrm{a})$ larger than are being currently measured $(8 \pm 4 \mathrm{~mm} / \mathrm{a})$. Another model suggested in this paper ignored the early formation of the TVZ, and considered only the 
latter stage of the TVZ, which was associated with the eastward motion of the NISB. Clearly, more research is needed to clarify these issues.

\section{Acknowledgments}

This paper is dedicated to Alex McNabb, on the occassion of his 70th birthday, for his encouragement and assistance in my mathematical modelling career. Thanks are also due to Micol Martini for computing most of the figures in this paper.

\section{References}

1. H. M. Bibby, T. G. Caldwell, F. J. Davey, and T. H. Webb. Geophysical evidence on the structure of the Taupo Volcanic Zone and its hydrothermal circulation, $J$. Volcanol. and Geothrm. Res., 68, 29 - 58, 1995.

2. C. Clauser and E. Huenges. Thermal Conductivity of Rocks and Minerals, Rock Physics and Phase Relations, A Handbook of Physical Constants, AGU Reference Shelf 3, ed. Thomas J. Ahrens, AGU, 1995.

3. J. W. Cole. Structural control and origin of volcanism in the Taupo volcanic zone, New Zealand, Bull. Volcanol., 52, 445 - 459, 1990.

4. F. J. Davey, S. A. Henrys and E. Lodolo. Asymmetric rifting in a continental backarc environment, North Island, New Zealand, J. Volcanol. and Geotherm. Res., 68, $209-238,1995$.

5. J. Elder. The bowels of the earth. Oxford University Press, 1976.

6. I. J. Graham, J. W. Cole, R. M. Briggs, J. A. Gamble and I. E. M. Smith. Petrology and petrogenesis of volcanic rocks from the Taupo Volcanic Zone : a review. $J$. Volcanol. and Geotherm. Res., 68, 59 - 87, 1995.

7. M. P. Hochstein. Crustal heat transfer in the Taupo Volcanic Zone (New Zealand): comparison with other volcanic arcs and explanatory heat source models, J. Volcanol. and Geotherm. Res., 68, 117 - 151, 1995.

8. A. McNabb. Geothermal physics, DSIR, Wellington, Appl. Math. Tech. Rep., 32, $37 \mathrm{pp}, 1975$.

9. A. McNabb. The Taupo-Rotorua Hot-Plate, Proc. 14th New Zealand Geothermal Workshop, University of Auckland, 14, 111 - 114, 1992.

10. A. McNabb and R. McKibbin. The Taupo-Rotorua Hot-Plate, submitted to Transport in Porous Media.

11. N. Modriniak and F. E. Studt. Geological structure and volcanism of the TaupoTarawera District. N.Z.J. Geol. Geophys., 2: 654 - 684, 1959.

12. S. F. Simmons and S. D. Weaver. Taupo Volcanic Zone, New Zealand, Special Issue, J. Volcanol. and Geotherm. Res., 68, 1 - 3, 1 238, 1995.

13. T. A. Stern. Asymmetric back-arc spreading, heat flux and structure associated with the Central Volcanic Region of New Zealand, Earth and Planetary Letters, $85,265-276,1987$.

14. T. A. Stern and F. J. Davey. A seismic investigation of crustal and upper mantle structure within the Central Volcanic Region of New Zealand. N.Z.J. Geol. Geophys., 30: 217 - 231, 1987. 
15. D. L. Turcotte and E. R. Oxburgh. Mantle Convection and the new global tectonics, Rev. Fluid Mechanics, 4, 33 - 68, 1972.

16. G. J. Weir. Transport Processes in the Taupo Volcanic Zone, New Zealand, J. Volcanol. and Geotherm. Res., 84, 61 - 72, 1998.

17. G. J. Weir. Conceptual models of heat transport in the Taupo Volcanic Zone, New Zealand. Proc. 20th NZ Geothermal Workshop, Auckland Unversity, Nov. 11 - 13, 159 - 164, 1998a.

18. L. E. Wilcox. Airy-Woollard Isostacy, in The Geophysics of the Pacific Ocean Basin and Its Margin, The Woollard Volume, geophysical monograph 19, AGU, Washington, 53 - 57, 1976.

19. C. J. N. Wilson, A. M. Rogan, I. E. M. Smith, D. J. Northey, I. A. Nairn, and B. F. Houghton. Caldera volcanoes of the Taupo Volcanic Zone, New Zealand. $J$. Geophys. Res., 89: 8463 - 8484, 1984.

20. C. J. N. Wilson. Statigraphy, chronology, styles and dynamics of late Quaternary eruptions from Taupo volcano, New Zealand. Philos. Trans. R. Soc., London, Ser. A, 343: $205-306,1993$.

21. C. J. N. Wilson, B. F. Houghton, M. O. McWillaims, M. A. Lanphere, S. D. Weaver and R. M. Briggs. Volcanic and structural evolution of Taupo Volcanic Zone, New Zealand: a review, J. Volcanol. and Geotherm. Res., 68, 1 - 28, 1995. 


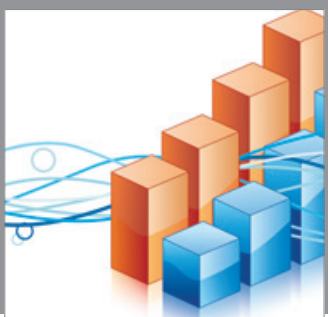

Advances in

Operations Research

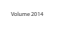

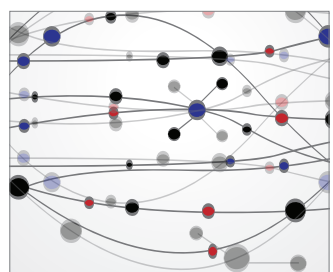

\section{The Scientific} World Journal
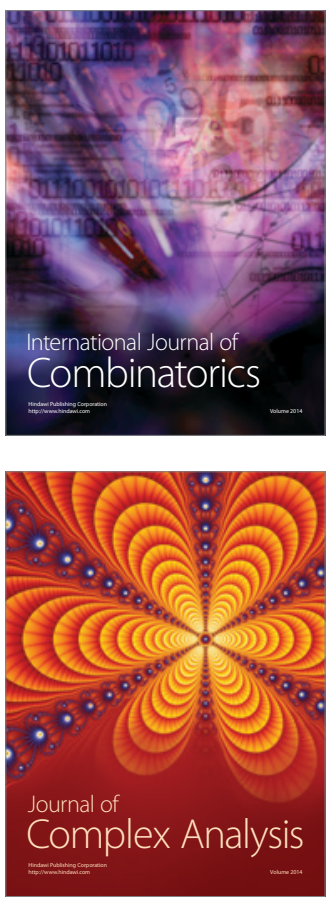

International Journal of

Mathematics and

Mathematical

Sciences
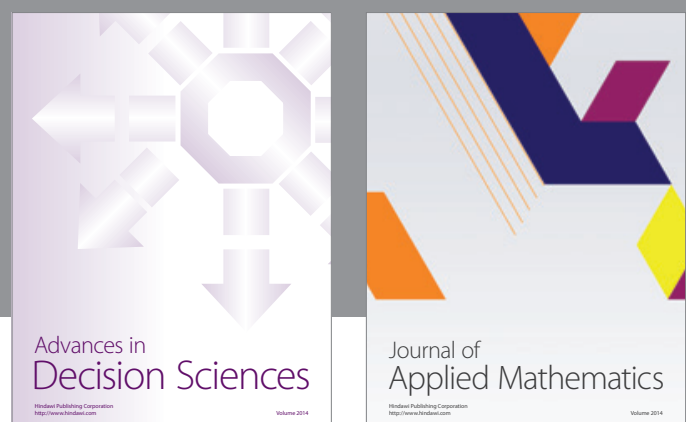

Journal of

Applied Mathematics
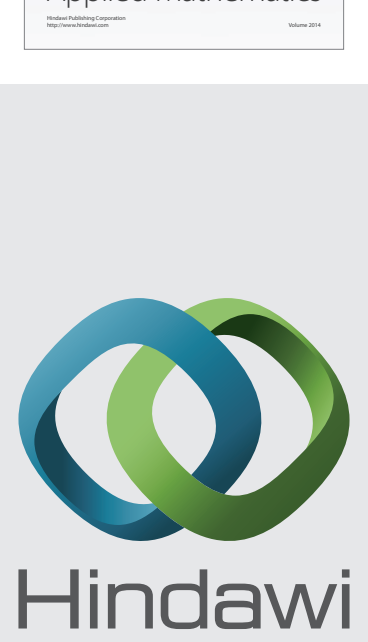

Submit your manuscripts at http://www.hindawi.com
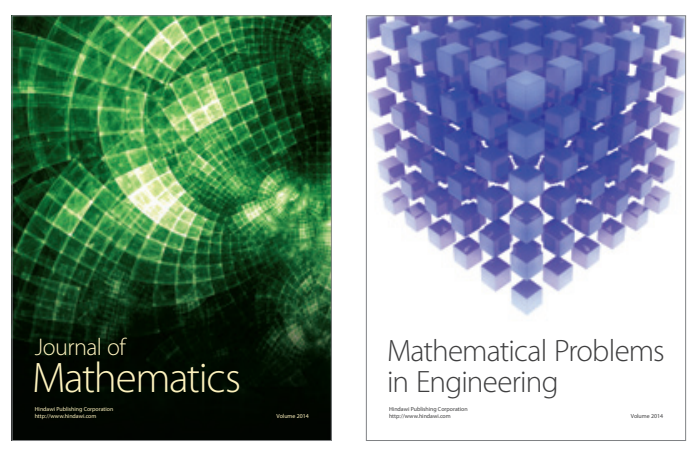

Mathematical Problems in Engineering
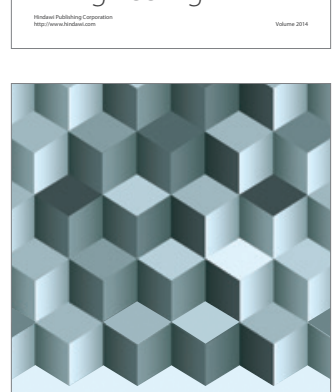

Journal of

Function Spaces
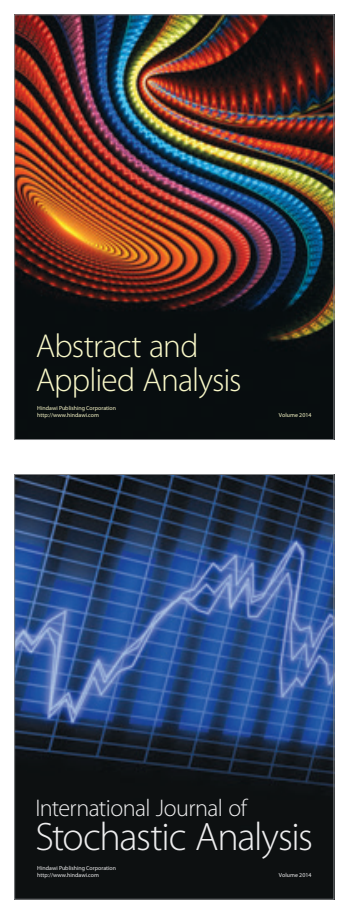

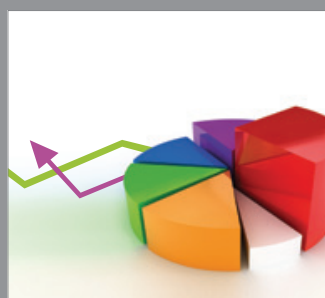

ournal of

Probability and Statistics

Promensencen
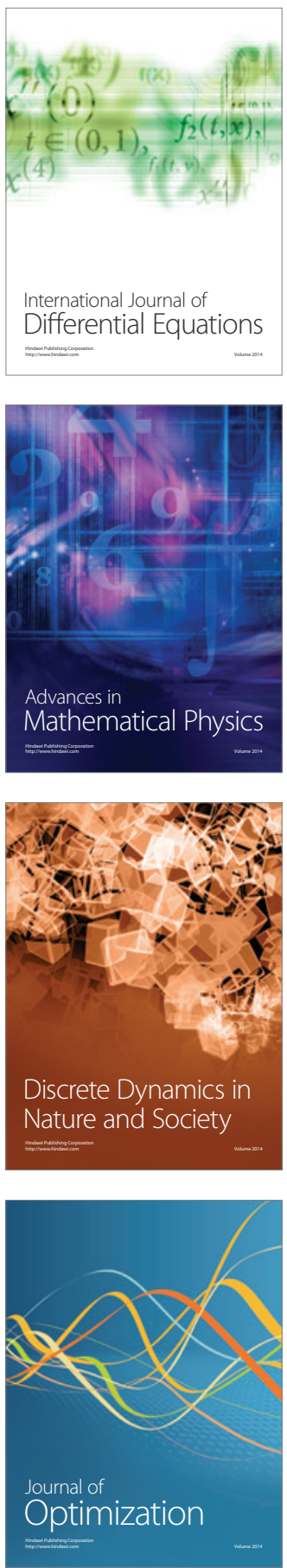